\title{
Emphasizing the Social Aspects of Learning to Foster Success of Students at Risk
}

Suzanne Brahmia, Rutgers University, 136 Frelinghuysen Road, PO Box 849, Piscataway, NJ, 08854-8019, brahmia@physics.rutgers.edu

Eugenia Etkina, Rutgers University

\begin{abstract}
The Extended Physics program at Rutgers University provides a successful alternative to the traditional introductory courses for students at risk of failure. We discuss methods for addressing problems that students at-risk face in introductory physics with special emphasis on the social aspects of learning. We share our experience in creating an effective program within the structure of a research university.
\end{abstract}

\section{Introduction}

Rutgers, The State University of N.J. is an urban, highly diverse research university. Over the past 12 years, Rutgers has significantly improved learning and retention of at-risk students. ${ }^{1,2,3}$ In this paper we discuss the factors that put students at risk of failure in introductory physics courses, and our methods, that emphasize the social aspects of learning, for addressing these factors.

\section{A Rise in the Number of Non- Traditional Physics Students}

The student population at Rutgers has become increasingly diverse in its gender and ethnic makeup, reflecting the national trend. $^{4,5}$ There are now over 250 more female and ethnic minority students taking physics than there were 15 years ago. We are teaching a greater number of students who are more likely to be at risk of failure or withdrawal from introductory physics courses. $^{6}$ These shifts warrant serious speculation about whom we are teaching and whom we are ignoring by using traditional methods of physics instruction.

\section{At-Risk Factors In Physics And The Methods That Are Used To Address Them}

Below are the features common to students who are at risk of failing or withdrawing from their introductory physics course, ${ }^{7,8}$ and proven methods for addressing them.

1. Low Confidence Level: Students have low expectations of their potential for success because physics is a difficult subject.

2. Lack of Community: Students who find few peers in the class (ethnic minorities and females) tend to feel much more strongly that they don't belong.

3. Weak Academic Preparation: Many of the ethnic minorities attending Rutgers are graduates of urban high schools located in low-income communities. They often have poorly developed study habits.

4. Unrealistic Expectations: In all courses there are students who hope to pass while doing almost no work.

Low confidence and lack of community are social issues. Methods for addressing these issues include group work, continuous feedback, follow-up on the performance in labs/exams, and ample availability of the course staff. ${ }^{9,10,11}$ Curving grades, which encourages competition over community and thus discourages the development of socialization between students should be avoided $^{12}$.

Weak academic preparation can be addressed by emphasizing scientific reasoning. ${ }^{13}$ Since weakly prepared students often don't see the connection between reality and its representations, ${ }^{14}$ for them direct experience should precede abstraction and generalization. 
We developed "Extended" Physics courses and recitations at Rutgers because we believe that failing students do not all have unrealistic expectations and can succeed in a different learning environment. What follows is our story of how we have successfully addressed the at-risk factors enumerated above by putting into action the suggestions found in the literature.

\section{Implementing the Methods}

The constraints on personalizing education at a large university are well known. How does one reduce section size, expect professional teaching practices from graduate students and provide a variety of assessment methods in an environment where large classes, tight scheduling, and few human resources are the norm?

The Department of Physics at Rutgers made a commitment to find the resources. ${ }^{15}$ It offers two different Extended Physics sequences (150-200 students in each course) that are stand-alone courses populated mainly by the students at risk of failure. Each is a parallel alternative (same content coverage) to the traditional introductory physics sequence. Extended Analytical Physics I (EAP I) is for engineering students in their first of two years and Extended General Physics (EGP) is a terminal physics course for computer and natural science majors. In both sequences the students meet twice weekly for recitation and twice weekly for lecture. In EGP the required lab is integrated with the course; in EAP I there is no required lab. Recitations are limited to an enrollment of 18 students.

In the fall semester 2000 Extended recitation sections that emphasized the social aspects of learning were offered for the first time to at risk engineering students in their second year of physics. ${ }^{16}$ The Extended sections were one component of an otherwise large traditional lecture course, no changes were made to either the lecture or the assessment tools. The Extended sections were more personalized and were based on cooperative- group learning methods. The sections were mainly populated by students who had taken EAP I during their first year of physics.

The underlying theme, both in the courses and in the recitation sections that we designed, is that through the development of the social aspects of learning we can greatly reduce the attrition of non-traditional students from SMET career options, for which physics is a prerequisite.

\section{Essential Features for Promoting the Social Aspect of Learning}

\section{(1) Group Work}

Group work is central to the structure of the program. It helps to eliminate the sense of isolation many minority and female students feel. The group work includes cooperative problem solving, qualitative hands-on activities, and quantitative labs. ${ }^{17}$ Students form teams of three, work throughout the term on all activities in the same team. The groups are evaluated both on group and on individual understanding.

\section{(2) Spiral curricular structure}

The course curriculum is broken into weekly themes corresponding to one or two chapters from the text. Each cycle begins with a lecture. The same theme is then immediately encountered in hands-on workshops and group problem solving. ${ }^{18}$ The learning cycle is completed with a large group discussion in lecture where the main ideas of the cycle are summarized.

Since different activities are based on different learning styles, one member of the group may best understand an idea when using experimental exploration, another may find a mathematical description more clear, while a third one might be most comfortable with a verbal description. Each member gains confidence by explaining to the group from their own perspective.

\section{(3) Course Coordinator}

The Course Coordinator (not a faculty member) provides integration between different elements of the cycle (a 
pedagogical function), cohesion amongst teaching staff (an organizational function), and encouragement and emotional support for students (a maternal/paternal function).

\section{(4) Assessment instruments}

Some of the assessment techniques used in many traditional introductory courses (such as timed multiple-choice tests) tend to favor highly confident and risk-taking students. ${ }^{19}$

The assessment system in Extended physics courses is radically different. The purpose is to create a non-competitive environment. The grading system does not curve. It works as a contract system: the tasks and rewards are specified before the work starts. For example, in one of the courses the midterm exams are worth 100 points, final is worth 200 points, workshop work is worth 260 points (broken down into smaller activities); HW is 60 pts. The final grade depends on the percentage of the total maximum number of points that is set up at the beginning of the course. No student feels that the success of their colleague comes at their own expense.

\section{(5) Role of lecture}

The lecture serves an important harmonizing function in our program. The lectures are interactive. The electronic Student Response System in our lecture hall is an important tool for creating interactivity. ${ }^{20}$ The lecturer knows and uses the names of the students during discussions. Many students attribute a large portion of their success to the friendliness and approachability of the teaching staff ${ }^{21}$.

\section{The Success of the Program}

The Extended Physics modifications to the engineering physics sequence have improved the success rates of at-risk students in engineering. The percentage of students who enroll in the engineering program as freshmen and complete their degree within five years has increased with the creation of Extended Analytical Physics. This retention rate has nearly doubled for female students and has increased by more than a factor of seven for black students (similar results are achieved for EGP students $^{22}$ ). In Figure 1 below we show the reduction of the number of non-traditional engineering students who abandon the second-year engineering physics course. The students for whom this program was designed are being well-served by the methods used in these courses.

Figure 1: Students abandoning the second year of physics before and after the option of Extended recitation sections

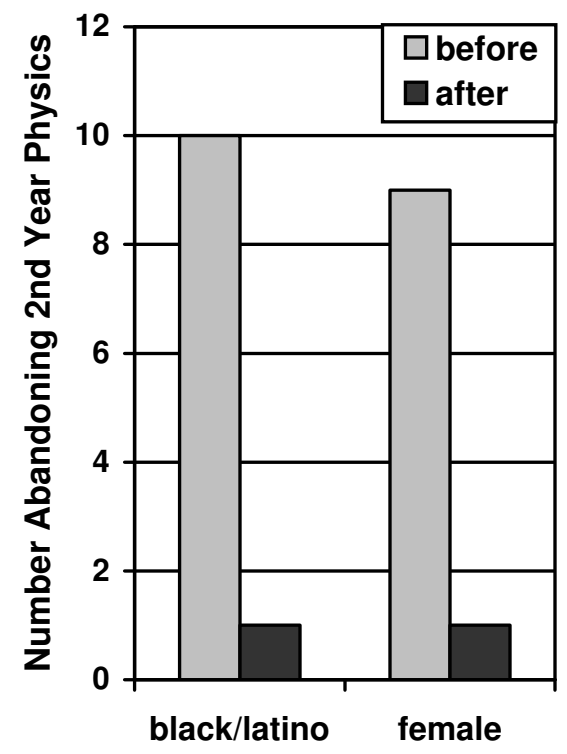

In spite of the variation in educational programming (EAP \& EGP) there are certain features that help the Extended physics model succeed. The course content and the sequence of topics follow the textbook used in each course just as is done in a traditional course. We believe it is the structure and instructional methods that determine whether the course helps students "at-risk" to learn physics.

\section{Summary}

Given the increasing diversity in preparation and background of our students, it is a professional obligation that we rethink the traditional delivery method in order to 
accommodate a variety of learning styles. Making significant and effective modifications to the large enrollment university science course is a non-trivial undertaking. In this paper we have discussed emphasizing the social aspects of learning as a means to developing a more inclusive introductory physics course based on our experience running and developing the Extended Physics program at Rutgers

1 S. Brahmia, "Extended analytical Physics: Report Presented at AAPT Summer Meeting"(1996).

Http://www.physics.rutgers.edu/ugrad/115_6/ext ended.html

${ }^{2}$ B. L. Holton and G. K. Horton, "The Rutgers Physics Learning Center: Reforming the Physics Course for First Year Engineering and Science Students", Phys. Teach. 34 (3), 138 - 143 (1996).

${ }^{3}$ E. Etkina, K. Gibbons, B. Holton, \& G. K. Horton, "Lessons Learned: A Case Study of an Integrated Way of Teaching Introductory Physics to At-Risk Students at Rutgers University". AJP, 67 (9), 810-818. 1999.

${ }^{4}$ A. Jones, \& B. Watson, High-Risk Students in higher Education: ASHER-ERIC Higher Education Reports, Washington DC (1993).

${ }^{5}$ J.H.F. Meyer, "Gender group differencies in the learning behavior of entering first-year university students", Higher Education 29 (2), 201-215 (1995).

${ }^{6}$ E. Seymour, 'The Problem Iceberg' in Science, Mathematics, and Engineering Education: Student Explanations for High Attrition Rates", Journal of College Science Teaching, 21 (4), 230-238 (1992); Guest Comment: Why undergraduates leave the sciences. American Journal of Physics, 63 (3), 199-202, (1995).

${ }^{7}$ See ref. 6 and L.C. McDermott, L. K. Piternick \& M. L. Rosenquist, Helping Minority Students Succeed in Science (Part 2). Journal of College Science Teaching, March, 201- 206. (1980).

${ }^{8}$ S. Frazier-Kouassi, O. Malanchuk, P. Shure, D. Burkam, P. Gurin, C. Hollenshead, D. Lewis, P. Soolner-Younce, H. Neal, \& C. Davis, "Women in Mathematics and Physics: Inhibitors and Enhancers", University of Michigan. (1992).

9 NECUSE, "Achieving Gender Equity in Science Classrooms", a guide for faculty. Office
University. In our program we simultaneously meet the needs of an at-risk population and function within the existing structure of a large research university.

*This work was supported by FIPSE grant P116B30151-95, and by several grants from the National Science Foundation and the General Electric Foundation, including DUE9254247 and USE92-51654.

of the Dean of the College at Brown University. (1996).

${ }^{10}$ Same as $6 \& 8$.

11 S. Tobias, They're Not Dumb, They're Different: Stalking the Second Tier, Research Corporation, Tucson, AZ, (1990);

S.Tobias, Revitalizing Undergraduate Science. Tuscon, Arizona: Research corporation (1992a); "Women in Science - Women and Science", Journal of College Science Teaching, 21 (5), 276-278 (1992b).

${ }^{12}$ Same as 9.

${ }^{13}$ M.C Linn, T. DeBenedictis, K. Delucchi, A. Harris, \& E. Stage, "Gender Differences in National Assessment of Educational Progress Science Items: What Does "I Don't Know" Really Mean?" Journal of Research in Science Teaching, 24 (3), 267-278 (1987)

${ }^{14}$ G. Banziger, "Women in Sciences, Program at Marietta College - Focusing on Math to Keep Women in Science", Journal of College Science Teaching, 21 (5), 279-281 91992), also see ref. 7.

${ }^{15}$ See ref. 11.

${ }^{16}$ S.Brahmia, G. Horton, A. Jordan, T. Devlin \& G. Thomson, "Fostering Success of At-Risk Students in a Large-Enrollement Electromagnetism course", Paper presented at 2001 AAPT Summer Meeting.

${ }^{17}$ L. Gautreau, L. Novemsky, "Concepts first - A small group approach to physics learning", Am.

J. Phys. 65 (5), 418 - 429 (1997).

${ }^{18}$ See ref. 3.

${ }^{19}$ See ref. 13.

${ }^{20}$ E. Mazur, Peer Instruction. New Jersey: Prentice Hall (1997); J. Shapiro, "Electronic Student Response System found feasible in Large Science Lecture Hall", Journal of College Science Teaching, XXVI, 408 - 412, (1997).

${ }^{21}$ See ref. 1.

${ }^{22}$ See ref. 3. 